\title{
Optimizing functions of coagulants in treatment of wastewater from metalworking fluids: Prediction by RSM method
}

\author{
Hamzeh Ali Jamali ${ }^{1}$, Maryam Moradnia ${ }^{2,3^{*}}$ \\ ${ }^{1}$ Department of Environmental Health Engineering School of Health, Qazvin University of Medical Sciences, Qazvin, Iran \\ ${ }^{2}$ Department of Environmental Health Engineering, School of Health Isfahan University of Medical Sciences, Isfahan, Iran \\ ${ }^{3}$ Health Network of Divandareh, Kurdistan University of Medical Sciences, Sanandaj, Iran
}

\begin{abstract}
Background: Coagulation is a treatment procedure for metalworking fluids (MWFs). This study aimed to optimize coagulation using four coagulants and compare the results.

Methods: In this research, the outputs of a coagulation procedure in chemical oxygen demand (COD) removal, turbidity, and the release of oil were investigated using four coagulants, ferric chloride $\left(\mathrm{FeCl}_{3}\right)$, ferric sulfate $\left(\mathrm{Fe}_{2}\left(\mathrm{SO}_{4}\right)_{3}\right.$, calcium chloride $\left(\mathrm{CaCl}_{2}\right)$, and aluminum sulfate $\left(\mathrm{Al}_{2}(\mathrm{SO} 4)_{3}\right.$. To optimize the process, a central composite design (CCD) and response surface methodology (RSM) were used. Results: Under optimal conditions for using calcium chloride (coagulant concentration $4.2 \mathrm{~g} / \mathrm{L}$ and $\mathrm{pH}$ 3.71), COD and turbidity removals and oil released were respectively $93 \%, 96.9 \%$, and $31.8 \mathrm{~mL}$. COD and turbidity removals and oil released using aluminum sulfate as a coagulant under optimal conditions $(5.36 \mathrm{~g} / \mathrm{L}, \mathrm{pH} 4.64)$ were $75.7 \%, 89.9 \%$, and $28.9 \mathrm{~mL}$, respectively. With respect to ferric sulfate under optimal conditions ( $6.25 \mathrm{~g} / \mathrm{L}, \mathrm{pH} 3.4)$, COD and turbidity removals were $60 \%$ and $84.1 \%$, respectively and oil released was $16.1 \mathrm{ml}$. COD and turbidity removals and the greatest amount of oil released by ferric chloride under optimal conditions $(3.16 \mathrm{~g} / \mathrm{L}, \mathrm{pH} 3.5)$ were $54.4 \%, 84.7 \%$, and $15.9 \mathrm{ml}$, respectively. Conclusion: Compared with other coagulants in the treatment of MWFs, calcium chloride achieved the highest removal efficiency in eliminating pollution indicators.

Keywords: Wastewater treatment, Metalworking fluids, Response surface methodology, Optimization Citation: Jamali HA, Moradnia M. Optimizing functions of coagulants in treatment of wastewater from metalworking fluids: Prediction by RSM method. Environmental Health Engineering and Management Journal 2018; 5(1): x-x. doi: 10.15171/EHEM.2018.xx.
\end{abstract}

\section{Article History:}

Received: 16 May 2017

Accepted: 11 November 2017

ePublished: 10 January 2018

*Correspondence to:

Maryam Moradnia

Email:

maryam.moradnia2000@gmail.com

\section{Introduction}

Industrial metalworking fluids (MWFs) have several applications in metalworking processes such as machining and lathe operations. While cooling down the manufactured parts and machining tools, these fluids lubricate and remove segregated work piece materials (1). More than 300 substances are employed in the production of different types of MWFs. The microbial degradation of water-miscible MWFs creates a wide range of problems, such as color changes in emulsion, lower quality workpieces, and unsatisfactory functioning of machining equipment. Likewise, high degrees of microbial loading may lead to health problems for the workers. MWFs lose their properties due to prolonged use and must be replaced with fresh MWFs (2). As a result, a large volume of wastewater containing chemical oxygen demand (COD) with high turbidity is generated; this discharge causes environmental risks and needs to be treated to meet discharge-related standards (3). Some treatment methods, such as chemical coagulation (4), and biological processes (5) were used to treat this kind of wastewater. Due to high concentrations of oil and antimicrobial agents, this type of wastewater cannot be thoroughly treated by means of biological processes; however, chemical coagulation is an appropriate procedure for treatment. The proper application of this process depends on careful scrutiny in selecting the amount of coagulant and the $\mathrm{pH}$. Classical methods have some limitations, like being highly timeconsuming because of the experiments and the high cost of consumables that can be removed by statistical experimental designs. Furthermore, in this method, it is impossible to examine the interactions among variables $(6,7)$. Response surface methodology (RSM) is a proper approach that also omits these limitations.

This study was conducted in 2014 at the School of Public Health of Qazvin University of Medical Sciences. It aimed to optimize the treatment of MWFs wastewater with four coagulants, ferric chloride, ferric sulfate, calcium chloride 
and aluminum chloride (aluminum sulfate), and compare their effectiveness in treatment. The main focus of this study was on optimization and modeling of the response and predictions. The optimization of parameters, modeling of response, and predictions were done by RSM.

\section{Methods}

In this study, four coagulant solutions (Merck, Germany), ferric chloride $\left(\mathrm{FeCl}_{3}\right)$, ferric sulfate $\left(\mathrm{Fe}_{2}\left(\mathrm{SO}_{4}\right)_{3}\right)$, calcium chloride $\left(\mathrm{CaCl}_{2}\right)$, and alum $\left(\mathrm{Al}_{2}\left(\mathrm{SO}_{4}\right)_{3}\right.$, were prepared and used during the study. Coagulation and flocculation processes were conducted by means of a conventional jar-test (made in Iran) apparatus with impellers equipped with six $1.5 \mathrm{~cm} \times 3.5 \mathrm{~cm}$ rectangular blades. Jar testing steps include rapid and slow mix with mixing speeds of 90 and $30 \mathrm{rpm}$, respectively. Times were set at 1 and 20 minutes for each step, respectively, while 30 minutes was considered as settling time. Central composite design (CCD) and RSM were applied to evaluate the relations between three responses (COD removal efficiency, turbidity, and amount of oil released) and two variables (amount of coagulant and $\mathrm{pH}$ ). Design Expert software (Stat-Ease Inc., Minneapolis, USA) was utilized for designing, statistical modeling, and optimization of the variables influencing the elimination of responses.

Before designing the research, the range of coagulant amounts to use and the $\mathrm{pH}$ were obtained through some preliminary experiments. The coagulant amounts ranged from $0.1 \mathrm{~g} / \mathrm{L}$ to the limit for appropriate reduction efficiency rates for COD and turbidity and increasing the amount of oil released. To find an effective range of $\mathrm{pH}$, a wide range from 2 to 12 was examined.

The ranges of $\mathrm{pH}$ and coagulant amounts were $\mathrm{pH}=2-6$ and 3-6 g/L for $\mathrm{FeCl}_{3}, \mathrm{pH}=3-7$ and 3-7 g/L for $\mathrm{Al}_{2} \mathrm{SO}_{4}$, $\mathrm{pH}=2.5-5.5$ and $4.5-6 \mathrm{~g} / \mathrm{L}$ for $\mathrm{Fe}_{2} \mathrm{SO}_{4}$, and $\mathrm{pH}=2-5$ and $2.5-5.5 \mathrm{~g} / \mathrm{L}$ for $\mathrm{CaCl}_{2}$. The maximum, median, and minimum values $(-1,-0.5,0,+0.5,+1)$ of each variable (including coagulant amounts (A) and $\mathrm{pH}(\mathrm{B})$ ) were specified based on CCD (Table 1).
In this study, the experimental design for each coagulant was performed based upon the full factorial design as $13\left(2^{k}+2 k\right)$, where $k$ is the number of factors $(=2)$ and 5 additional experiments were performed as the reproducibility of center point. Totally 52 experiments were carried out for four coagulants.

The second-order model equation used to describe the system behavior can be stated as the following:

$Y=\beta_{0}+\sum_{i=1}^{K} \beta i \cdot X i+\sum_{i=1}^{K} \beta i i \cdot X i^{2}+\sum_{i i \leq j}^{K} \sum_{j}^{K} \beta i j . X i . X j+\cdots+e$

where $\mathrm{Y}, \mathrm{i}, \mathrm{j}, \beta$, e, and $\mathrm{k}$ are the response variable, linear constant, quadratic constant, regression constant, random error, and number of parameters, respectively.

Analysis of variance (ANOVA) was performed for model selection. Significant model terms were identified at 95\% when the modified model was obtained through the elimination of non-significant factors.

For graphic analysis of the data and to determine the interactive effects between the independent variables of the process and responses, ANOVA was performed. The quality of the model fitting was determined by $\mathrm{R}^{2}$ and adjusted $\mathrm{R}^{2}$ determination coefficient, and the Fischer test (F-test) was used for statistical significance; $P \leq 0.05$ was determined as the significance level.

Following the analysis of experimental data, optimal conditions were determined graphically. Two-dimensional plots for the four coagulants $\left(\mathrm{FeCl}_{3}, \mathrm{Fe}_{2}\left(\mathrm{SO}_{4}\right)_{3}, \mathrm{CaCl}_{2}\right.$ and $\left.\mathrm{Al}_{2}\left(\mathrm{SO}_{4}\right)_{3}\right)$ were plotted based on the effects of the two factors (coagulant amount and $\mathrm{pH}$ ) in five levels. Furthermore, numerical optimization was performed for the four coagulates, selecting "in range" for both factors (coagulant dose and $\mathrm{pH}$ ) and putting all responses in maximized mode. With numerous responses, the optimum conditions where all variables concurrently met the desirable removal criteria could be plotted graphically by overlaying the response surface contours in an overlay diagram. Graphical optimizations for various parameters were determined by overlaying the contour plots. To

Table 1. Independent variables and experimental levels for response surface study

\begin{tabular}{|c|c|c|c|c|c|}
\hline \multirow{2}{*}{ Independent variable } & \multicolumn{5}{|c|}{ Coded levels } \\
\hline & -1 & -0.5 & 0 & +0.5 & +1 \\
\hline \multicolumn{6}{|c|}{$\mathrm{FeCl}_{3}$} \\
\hline A: Dose (g/L) & 2.00 & 3.00 & 4.00 & 5.00 & 6.00 \\
\hline $\mathrm{B}: \mathrm{pH}$ & 2.00 & 3.00 & 4.00 & 5.00 & 6.00 \\
\hline \multicolumn{6}{|c|}{$\mathrm{CaCl}_{2}$} \\
\hline A: Dose (g/L) & 2.50 & 3.25 & 4.00 & 4.75 & 5.50 \\
\hline $\mathrm{B}: \mathrm{pH}$ & 2.00 & 2.75 & 3.50 & 4.25 & 5.00 \\
\hline \multicolumn{6}{|c|}{$\mathrm{Fe}_{2}\left(\mathrm{SO}_{4}\right)_{3}$} \\
\hline A: Dose (g/L) & 4.50 & 5.25 & 6.00 & 6.75 & 7.50 \\
\hline $\mathrm{B}: \mathrm{pH}$ & 2.50 & 3.25 & 4.00 & 4.75 & 5.50 \\
\hline \multicolumn{6}{|c|}{$\mathrm{Al}_{2}\left(\mathrm{SO}_{4}\right)_{3}$} \\
\hline A: Dose (g/L) & 4.50 & 5.25 & 6.00 & 6.75 & 7.50 \\
\hline $\mathrm{B}: \mathrm{pH}$ & 2.50 & 3.25 & 4.00 & 4.75 & 5.50 \\
\hline
\end{tabular}


confirm the agreement of the results obtained from the model and the real conditions using each coagulant, two extra experiments were performed utilizing the optimal circumstances.

\section{Results}

Based on the experimental results, CCD values for the four coagulants are presented in Table 2. According to the obtained results, the highest $\mathrm{COD}$ removal efficiency rates of $\mathrm{FeCl}_{3}, \mathrm{CaCl}_{2}$, Alum, and $\mathrm{Fe}_{2}\left(\mathrm{SO}_{4}\right)_{3}$ were $56 \%, 96.1 \%$, $81 \%$, and $67 \%$, respectively. The highest percentages of turbidity removal by the four mentioned coagulants were $98 \%, 100 \%, 94 \%$, and $97.1 \%$, respectively. The amounts of oil released were $17.2 \mathrm{~mL}, 36 \mathrm{~mL}, 30 \mathrm{~mL}$, and $15 \mathrm{~mL}$, respectively.

The results obtained from ANOVA for the removal of COD and turbidity, the amount of oil released, and the modified models are presented in Table 3.

Using $\mathrm{CaCl}_{2}$ under optimal conditions (coagulant concentration $=4.2 \mathrm{~g} / \mathrm{L} ; \mathrm{pH}=3.3$ ), COD and turbidity removal rates and the amount of oil released were $93 \%$, $96.9 \%$, and $31.8 \mathrm{ml}$, respectively. COD and turbidity removal rates and the amount of oil released by aluminum sulfate as coagulant under optimal conditions (coagulant concentration $=5.36 \mathrm{~g} / \mathrm{L} ; \mathrm{pH}=4.64)$ were $75.7 \%, 89.9 \%$, and $28.9 \mathrm{ml}$, respectively. With respect to $\mathrm{Fe}_{2}\left(\mathrm{SO}_{4}\right)_{3}$ under optimal conditions (6.25 g/L, pH 3.4), COD and turbidity removal rates and the amount of oil released were $60 \%$, $84.1 \%$, and $16.1 \mathrm{ml}$, respectively. COD and turbidity removal rates and the highest amount of oil released by $\mathrm{FeCl}_{3}$ under optimal conditions (3.16 g/L and pH 3.5) were $54.4 \%, 84.7 \%$, and $15.9 \mathrm{ml}$, respectively. The desirability of the models for each coagulant was found to be $93.6 \%$, $87.6 \%, 91.2 \%$, and $85 \%$, respectively.

The contour plots for the effective factors in reducing COD and turbidity and increasing the amount of oil released by the four coagulants are plotted in Figures 1 to 3.

By overlaying the four contour plots, the optimum removal efficiencies for COD and turbidity, and the amount of oil released were obtained and are shown in Figure 4.

\section{Discussion}

The lack of fit (LOF) defines the variation of data around the fitted model. If the model does not fit the data well, this test will be significant (8). In this study, the lack of fit test was not significant for any of the responses, indicating a good fit of the data to the model.

The coefficient of determination $\left(\mathrm{R}^{2}\right)$ expresses the quality of the quadratic polynomial model fit. This parameter shows the ratio of the sum of squares of regression (SSR)

Table 2. CCD values for the four coagulants

\begin{tabular}{|c|c|c|c|c|c|c|c|c|c|c|c|}
\hline \multirow{2}{*}{ Run } & \multicolumn{2}{|c|}{ Parameter } & \multicolumn{3}{|c|}{ Responses } & \multirow{2}{*}{ Run } & \multicolumn{2}{|c|}{ Parameter } & \multicolumn{3}{|c|}{ Responses } \\
\hline & pH & Dose (g/L) & COD (\%) & Turbidity (\%) & Oil (mL) & & $\mathrm{pH}$ & Dose $(\mathrm{g} / \mathrm{L})$ & COD (\%) & Turbidity (\%) & Oil (mL) \\
\hline $\mathrm{FeCl}_{3}$ & \multicolumn{11}{|c|}{$\mathrm{Al}_{2}\left(\mathrm{SO}_{4}\right)_{3}$} \\
\hline 1 & 4.00 & 3.00 & 51.00 & 84.40 & 14.40 & 1 & 5.50 & 5.00 & 62.50 & 94.00 & 24.00 \\
\hline 2 & 4.00 & 4.00 & 50.00 & 90.00 & 14.00 & 2 & 4.00 & 3.00 & 20.00 & 30.00 & 5.00 \\
\hline 3 & 2.00 & 6.00 & 28.00 & 52.50 & 7.00 & 3 & 5.00 & 6.00 & 65.30 & 80.00 & 28.00 \\
\hline 4 & 4.00 & 4.00 & 48.00 & 94.00 & 12.00 & 4 & 5.00 & 5.00 & 78.30 & 92.00 & 29.00 \\
\hline 5 & 2.00 & 2.00 & 56.00 & 50.00 & 17.20 & 5 & 5.00 & 5.00 & 78.00 & 89.00 & 29.00 \\
\hline 6 & 6.00 & 2.00 & 16.00 & 56.00 & 3.00 & 6 & 4.00 & 7.00 & 58.80 & 58.00 & 25.00 \\
\hline 7 & 4.00 & 4.00 & 49.30 & 89.00 & 13.50 & 7 & 6.00 & 7.00 & 20.00 & 49.00 & 3.00 \\
\hline 8 & 4.00 & 4.00 & 50.00 & 88.00 & 15.00 & 8 & 4.50 & 5.00 & 68.50 & 88.00 & 30.00 \\
\hline 9 & 4.00 & 4.00 & 54.50 & 98.00 & 16.00 & 9 & 5.00 & 4.00 & 66.50 & 83.00 & 21.00 \\
\hline 10 & 5.00 & 4.00 & 35.50 & 85.00 & 9.80 & 10 & 6.00 & 3.00 & 25.40 & 51.50 & 5.00 \\
\hline 11 & 3.00 & 4.00 & 50.50 & 79.00 & 15.00 & 11 & 5.00 & 5.00 & 64.10 & 91.00 & 17.00 \\
\hline 12 & 6.00 & 6.00 & 14.00 & 66.10 & 3.00 & 12 & 5.00 & 5.00 & 81.00 & 90.00 & 27.00 \\
\hline 13 & 4.00 & 5.00 & 40.50 & 86.00 & 13.00 & 13 & 5.00 & 5.00 & 80.60 & 93.00 & 27.00 \\
\hline $\mathrm{CaCl}_{2}$ & \multicolumn{11}{|c|}{$\mathrm{Fe}_{2}\left(\mathrm{SO}_{4}\right)_{3}$} \\
\hline 1 & 3.50 & 4.00 & 90.50 & 94.00 & 30.00 & 1 & 4.00 & 6.00 & 67.00 & 97.10 & 15.00 \\
\hline 2 & 3.50 & 4.00 & 89.00 & 94.00 & 29.00 & 2 & 2.50 & 4.50 & 24.50 & 38.00 & 5.40 \\
\hline 3 & 3.50 & 4.75 & 88.00 & 93.00 & 27.00 & 3 & 3.25 & 6.00 & 54.00 & 80.00 & 12.10 \\
\hline 4 & 4.25 & 4.00 & 90.00 & 96.00 & 30.00 & 4 & 4.00 & 6.00 & 65.00 & 97.00 & 14.00 \\
\hline 5 & 2.75 & 4.00 & 94.00 & 96.00 & 28.00 & 5 & 4.00 & 6.00 & 61.00 & 97.00 & 12.50 \\
\hline 6 & 3.50 & 4.00 & 96.10 & 100 & 36.00 & 6 & 5.50 & 4.50 & 19.00 & 30.00 & 4.50 \\
\hline 7 & 3.50 & 4.00 & 92.60 & 98.00 & 32.00 & 7 & 4.00 & 5.25 & 49.00 & 81.00 & 11.40 \\
\hline 8 & 3.50 & 3.25 & 89.00 & 90.00 & 29.00 & 8 & 4.00 & 6.00 & 56.00 & 95.00 & 13.00 \\
\hline 9 & 5.00 & 5.50 & 67.00 & 80.00 & 13.00 & 9 & 5.50 & 6.75 & 53.00 & 85.50 & 13.50 \\
\hline 10 & 5.00 & 2.50 & 46.40 & 62.00 & 1.00 & 10 & 2.50 & 7.50 & 25.00 & 35.00 & 5.20 \\
\hline 11 & 2.00 & 5.50 & 60.50 & 80.00 & 14.00 & 11 & 5.50 & 7.50 & 51.50 & 61.00 & 10.20 \\
\hline 12 & 3.50 & 4.00 & 91.00 & 94.00 & 31.00 & 12 & 4.75 & 6.00 & 59.00 & 86.00 & 12.40 \\
\hline 13 & 2.00 & 2.50 & 65.20 & 75.00 & 6.00 & 13 & 4.00 & 6.00 & 63.00 & 97.10 & 14.00 \\
\hline
\end{tabular}


Table 3. ANOVA results for removal of COD and turbidity and the amount of oil released using the four coagulants

\begin{tabular}{|c|c|c|c|c|c|c|c|c|}
\hline Response & Final equation in term of code factor & $\boldsymbol{P}$ & PLOF & $\mathbf{R}^{2}$ & Adj. $R^{2}$ & AP & CV & SD \\
\hline \multicolumn{9}{|c|}{$\mathrm{FeCl}_{3}$} \\
\hline COD & $4896 / 83 / 7-A-1367 / B+65 / A B-1586 / B^{2}$ & $<0.0001$ & 0.30 & 0.98 & 0.96 & 22.56 & 6.71 & 2.81 \\
\hline Turbidity & $9019 /+502 / B-2356 / B^{2}$ & $<0.0001$ & 0.60 & 0.97 & 0.94 & 15.37 & 4.94 & 3.87 \\
\hline Oil released & $1401 /-243 / A-462 / B-255 / A B-594 / B^{2}$ & $<0.0001$ & 0.90 & 0.96 & 0.94 & 17.68 & 10.15 & 1.19 \\
\hline \multicolumn{9}{|c|}{$\mathrm{CaCl}_{2}$} \\
\hline COD & $9288 /+342 / A-318 / B+6933 / A B-2346 / A^{2}$ & $<0.0001$ & 0.42 & 0.98 & 0.97 & 24.00 & 3.44 & 2.80 \\
\hline Turbidity & $982 /+544 / A 89 / 2-B+325 / A B-1996 / A^{2}$ & $<0.0001$ & 0.78 & 0.97 & 0.95 & 21.00 & 2.72 & 2.41 \\
\hline Oil released & $3151 /+422 / A$ & $<0.0001$ & 0.40 & 0.96 & 0.93 & 15.20 & 12.10 & 2.84 \\
\hline \multicolumn{9}{|c|}{$\mathrm{Fe}_{2}(\mathrm{SO} 4)_{3}$} \\
\hline COD & $6042 /+778 / A+522 / B+8 A B 39 / 26-A^{2}$ & 0.006 & 0.43 & 0.96 & 0.93 & 14.56 & 8.70 & 4.30 \\
\hline Turbidity & $36.72+A-4.67 B 8.5+A B 25.74 A^{2} 26.74-B^{2}$ & $<0.0001$ & 0.11 & 0.98 & 0.97 & 23.90 & 5.18 & 3.88 \\
\hline Oil released & $13.221 .45+A 0.94+B+1.47 A B 4.02-B^{2}$ & 0.0044 & 0.81 & 0.97 & 0.94 & 16.51 & 7.45 & 0.82 \\
\hline \multicolumn{9}{|c|}{$\mathrm{Al}_{2}\left(\mathrm{SO}_{2}\right)_{3}$} \\
\hline COD & 7424/- 809/B - 1105/ AB & 0.0002 & 0.60 & 0.94 & 0.91 & 12.43 & 11.10 & 6.56 \\
\hline Turbidity & $9132 /+533 / A+344 / B-762 / A B-4107 / A^{2}$ & $<0.0001$ & 0.06 & 0.99 & 0.98 & 32.57 & 3.65 & 2.78 \\
\hline Oil released & $2665 /+478 / A-556 / B-55 / A B$ & 0.0018 & 0.91 & 0.91 & 0.84 & 9.21 & 19.40 & 4.00 \\
\hline
\end{tabular}

to total sum of squares (SST) $(9,10)$. The high value of $\mathrm{R}^{2}$ shows the satisfactory agreement of the experimental data with the quadratic model. In all cases of this study, the values of $\mathrm{R}^{2}$ were found to be higher than 0.9 for all responses; thus, it can be said that the quadratic model has a good fitness for the data.

In other words, AP compares the mean prediction error with the range of values predicted at design points. Ratios above 4 show the adequacy of the models (11). In this research, the AP values for all responses were greater than 4 , indicating the high predictive ability of this model in the obtained results.

The coefficient of variation is a measure of the residual variation of the data relative to the size of the mean. It is the standard deviation divided by the dependent mean
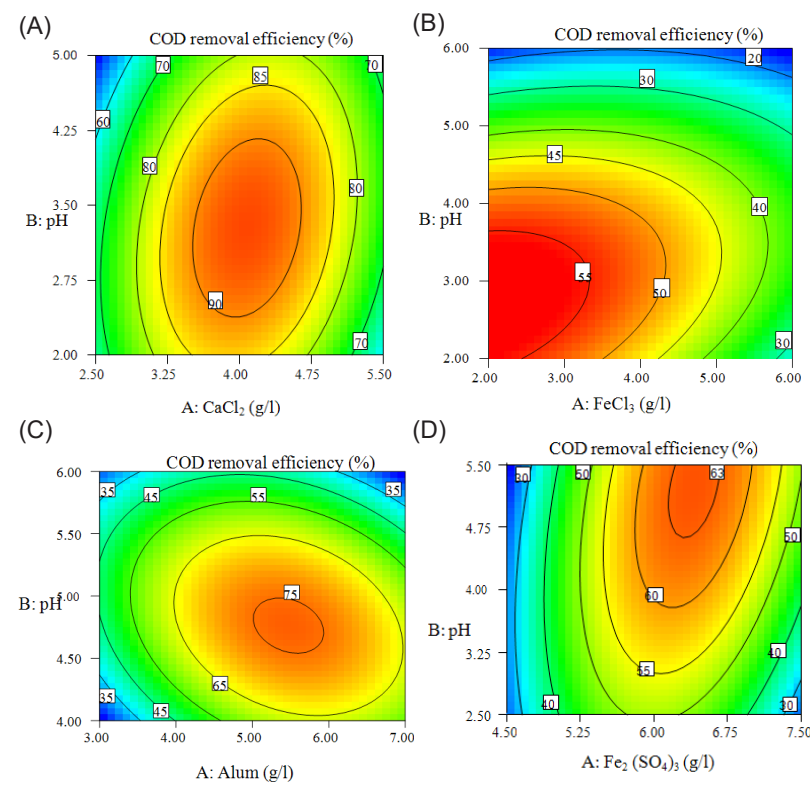

(D)

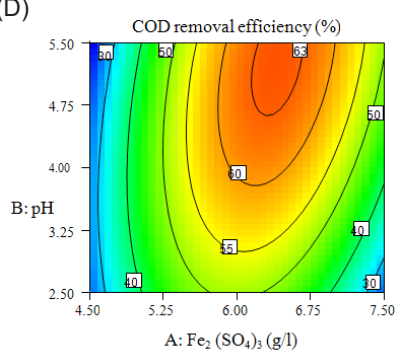

Figure 1. The contour plots for the removal of COD using (A) $\mathrm{CaCl}_{2}$, (B) $\mathrm{FeCl}_{3}$, (C) alum, and (D) $\mathrm{Fe}_{2}\left(\mathrm{SO}_{4}\right)_{3}$. and expressed as a percentage. The coefficient of variation $(\mathrm{CV})$ is very low, indicating that the experimental values have a very high degree of precision and a good deal of reliability. Typically, a model will be considered as reproducible when its $\mathrm{CV}$ value is within the acceptable range of $10 \%$ (12). In this study, the values of CV for all responses except the amount of oil released and the removal of COD by alum were not greater than $10 \%$, which demonstrates high precision in the results and the reproducibility of the model.

Figure 4A illustrates an overlay scheme of the optimum condition for $\mathrm{CaCl}_{2}$. According to this diagram, the optimal area for the three responses, COD, turbidity, and the amount of oil released, was a concentration range of 3-4.5 g/L and a $\mathrm{pH}$ range of $2.75-4$. In this area, the
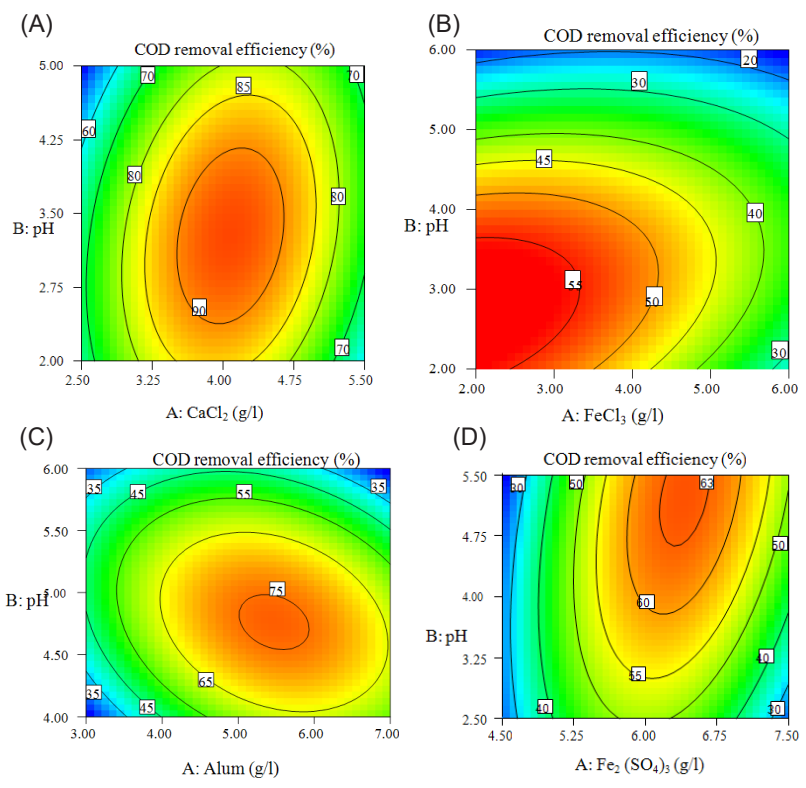

Figure 2. The contour plots for the removal of turbidity using (A) $\mathrm{CaCl}_{2}$, (B) $\mathrm{FeCl}_{3}$, (C) alum, and (D) $\mathrm{Fe}_{2}\left(\mathrm{SO}_{4}\right)_{3}$. 

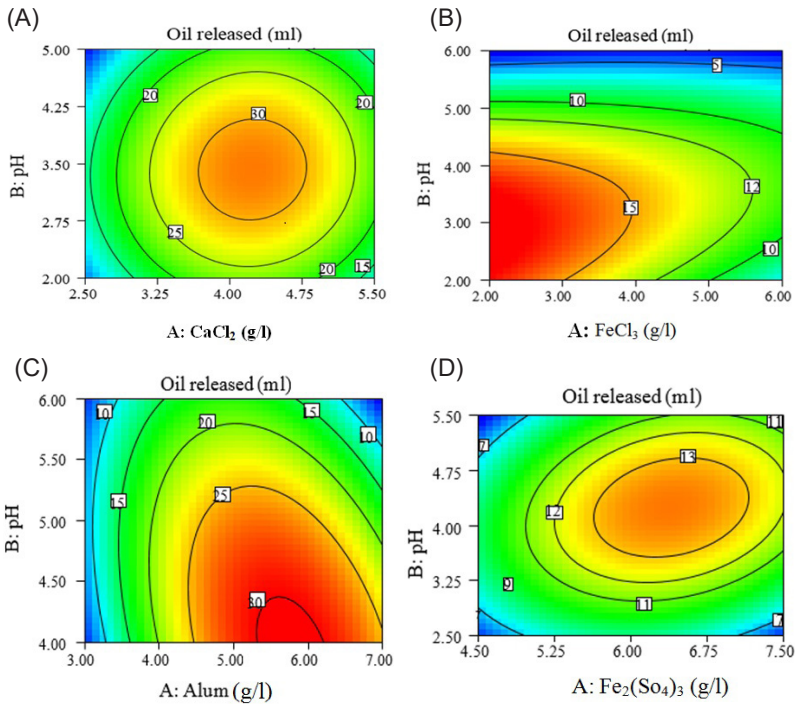

(D)

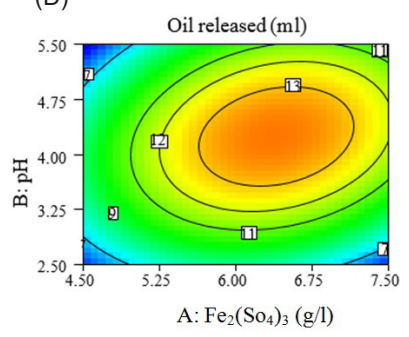

Figure 3. The contour plots for the amount of oil released using (A) $\mathrm{CaCl}_{2}$, (B) $\mathrm{FeCl}_{3}$, (C) alum, and (D) $\mathrm{Fe}_{2}\left(\mathrm{SO}_{4}\right)_{3}$.

minimum removal values for COD and turbidity and the amount of oil released were $85 \%, 95 \%$, and $30 \mathrm{~mL}$, respectively. The results of a research on the application of aluminum chloride and $\mathrm{CaCl}_{2}$ in a combined treatment method incorporating MWF emulsion destabilization and vacuum filtration illustrated that aluminum chloride left a minimal effect on the destabilization of MWF emulsion, while a $0.05 \mathrm{~mol} / \mathrm{L}$ concentration of $\mathrm{CaCl}_{2}$ increased the efficiency of this combined system in removing COD up to $90 \%$ (13). This confirms the desirability of using aluminum chloride in the treatment of MWFs. Similarly, the results from the application of $\mathrm{CaCl}_{2}$ along with a cationic coagulant as an emulsion breaker in the treatment of industrial wastewater containing oily materials demonstrated that in a concentration of $1 \mathrm{~g} / \mathrm{L}$ of this chemical compound, the COD removal efficiency was $90 \%$, which was largely consistent with the results of the current research (14). The lack of complete emulsification of oil in an aqueous solution was considered as the reason for the lower consumption of this coagulant (15).

With respect to the $\mathrm{FeCl}_{3}$ graph presented in Figure 4B, a concentration of 3.25-5 g/L and a $\mathrm{pH}$ range of 3-4 were optimum conditions of the process factors for the three responses related to COD removal, turbidity, and the amount of oil released. In order to achieve this condition, the minimum removal of COD and turbidity and the amount of oil released were selected $40 \%, 85 \%$, and $13 \mathrm{~mL}$, respectively.

As can be observed in Figure 4C, for the coagulant alum, a concentration of 4.5-5.5 g/L within a $\mathrm{pH}$ range of 4.55.4 was optimum, and the minimum removal rates of COD, turbidity, and the amount of oil released were $70 \%$, $85 \%$, and $20 \mathrm{~mL}$, respectively. The treatment of industrial MWFs using electrocoagulation with aluminum electrode indicated that increasing $\mathrm{pH}$ will raise the removal rates of turbidity and COD. In this case, the removal efficiencies
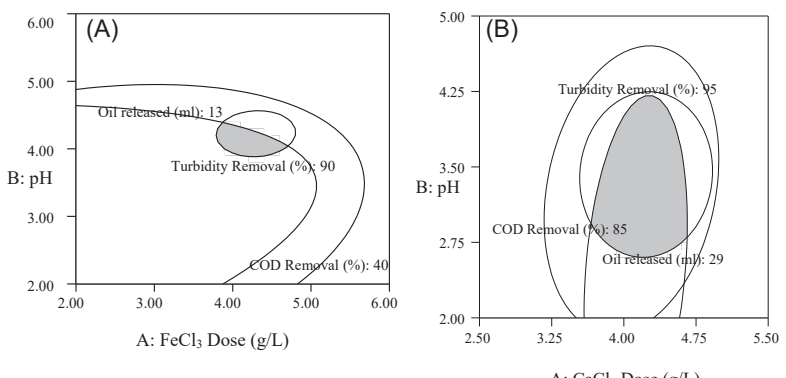

A: $\mathrm{CaCl}_{2}$ Dose $(\mathrm{g} / \mathrm{L})$
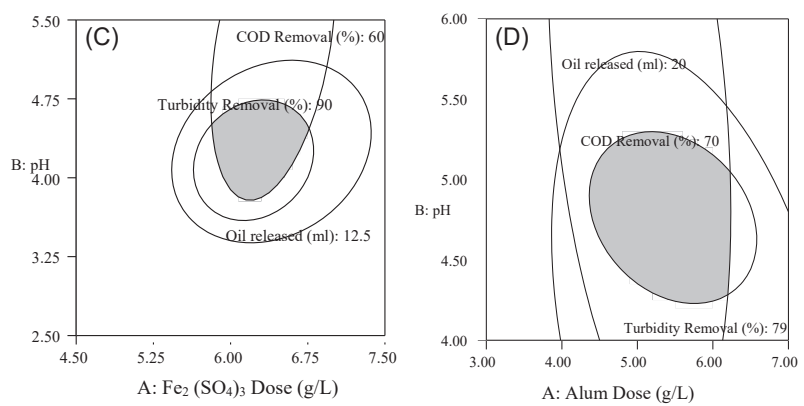

Figure 4. The overlaying plots for the removal of COD and turbidity, and the amount of oil released using (A) $\mathrm{CaCl}_{2}$, (B) $\mathrm{FeCl}_{3},(\mathrm{C})$ alum, and (D) $\mathrm{Fe}_{2}\left(\mathrm{SO}_{4}\right)_{3}$.

for COD and turbidity were $92 \%$ and $99 \%$, respectively, indicating the good effectiveness of aluminum in removing these two contaminants from industrial wastewater. Canizares et al reported that $\mathrm{pH}$ has a strong influence on the COD removal from oil-water emulsion by alum destabilization. They reported that the best results are only attained in a $\mathrm{pH}$ range of 5-9; that is somewhat consistent with the current results (16). Aluminum species present in an aqueous solution depend on the aluminum concentration and $\mathrm{pH}$. In this point of attitude, it is more important to take into account that the aqueous chemistry of aluminum is especially complex, as it involves the formation of polymeric hydroxo-aluminum ions and monomeri and precipitates of aluminum hydroxide. Thus, the primary species are monomeric, cationic hydroxoaluminum species in acidic conditions. Increasing the $\mathrm{pH}$ causes the coexistence of these monomeric species with rising polymeric cations and precipitates. At the neutrality condition of $\mathrm{pH}$, the main species are the aluminum hydroxide precipitates that can be completely charged; however, increases in $\mathrm{pH}$ produce the reversal charge, leading to negatively-charged precipitates. Additional increases in the $\mathrm{pH}$ cause the dissolution of precipitates to monomeric anionic hydroxo-aluminum form, which is the primary species at alkaline pHs (17).

Figure 4D illustrates an overlay scheme for the characterization of the optimum point for the $\mathrm{Fe}_{2}$ $\left(\mathrm{SO}_{4}\right)_{3}$ coagulant. For the three responses, the optimum conditions were a concentration of 5.25-6.75 g/L and a $\mathrm{pH}$ range of 3.7-4.7. In order to achieve this condition, the minimum removal rates of COD and turbidity and the amount of oil released selected were $60 \%, 90 \%$, and 13.5 
Table 5. Verification of experimental results at optimum conditions

\begin{tabular}{|c|c|c|c|c|c|}
\hline Responses & & $\mathrm{CaCl}_{2}$ & $\mathrm{Fecl}_{3}$ & $\mathrm{Fe}_{2}\left(\mathrm{SO}_{4}\right)_{3}$ & $\mathrm{Al}_{2}\left(\mathrm{SO}_{2}\right)_{3}$ \\
\hline \multirow{3}{*}{ Experimental results } & COD removal efficiency (\%) & 97.00 & 50.00 & 62.00 & 74.10 \\
\hline & Turbidity removal efficiency (\%) & 98.00 & 81.00 & 86.00 & 85.00 \\
\hline & Oil released $(\mathrm{mL})$ & 34.20 & 14.30 & 25.00 & 27.00 \\
\hline \multirow{3}{*}{ Model response } & COD removal efficiency (\%) & 93.00 & 54.40 & 60.00 & 75.70 \\
\hline & Turbidity removal efficiency (\%) & 96.90 & 84.70 & 84.10 & 89.90 \\
\hline & Oil released $(\mathrm{mL})$ & 31.80 & 15.90 & 28.90 & 28.90 \\
\hline \multirow{3}{*}{$\begin{array}{l}\text { Error and standard } \\
\text { deviation }\end{array}$} & COD removal efficiency (\%) & $4 \pm 1.50$ & $-4.4 \pm 1.7$ & $2 \pm 1.10$ & $-1.6 \pm 0.25$ \\
\hline & Turbidity removal efficiency (\%) & $1.1 \pm 0.50$ & $-3.7 \pm 1.1$ & $1.9 \pm 0.30$ & $-4.9 \pm 0.60$ \\
\hline & Oil released $(\mathrm{mL})$ & $2.4 \pm 1.65$ & $-1.6 \pm 0.40$ & $-3.9 \pm 0.55$ & $-1.9 \pm 0.50$ \\
\hline
\end{tabular}

$\mathrm{mL}$, respectively. Tir and Moulai-Mostefa used alum and $\mathrm{Fe}_{2}\left(\mathrm{SO}_{4}\right)_{3}$ for waste oil/water emulsion treatment. Their results indicated reductions in turbidity and COD by the mentioned coagulants. The effectiveness of wastewater treatment is better with alum than with the addition of $\mathrm{Fe}_{2}$ $\left(\mathrm{SO}_{4}\right) 3$; this result is in agreement with the current results. These coagulant agents, which usually help to increase separation effectiveness, cause a physicochemical effect which is used to destabilize emulsion and increase droplet size. In fact, an increase in metal sulfate concentration leads to the acceleration of flocculation and, consequently, an increase in the size of flocs (18). Zhang et al compared the performances of $\mathrm{CaCl}_{2}$, sodium chloride, $\mathrm{FeCl}_{3}$, polymeric ferric sulfate, ferrous sulfate, and polyaluminum chloride as emulsion breakers in the treatment of MWFs. The results demonstrated that with an equal consumption of each coagulant $(3 \mathrm{~g} / \mathrm{L})$, the COD removal efficiencies of each coagulant were $85 \%, 58 \%, 49 \%, 40 \%, 46 \%$, and $46 \%$, respectively (19). The attachment of adsorbing macromolecules to more droplets by means of bridging flocculation is the main mechanism of destabilization. This mechanism inducts electrically-charged species as reagents, and these species can join through attractive electrical forces with oppositely charged active sites which are present on the droplet surface. Furthermore, to bridge flocculation, some researchers have indicated the oil removal from emulsified effluents through adsorption properties by increasing metal hydroxides in the coagulation-flocculation method (1-3). The efficiencies of oil removal were reported as $65 \%, 85 \%, 60 \%, 53 \%, 50 \%$, and $50 \%$, respectively. These results were in agreement with those of the current study and indicated the good performance of $\mathrm{CaCl}_{2}$ compared to other coagulants. The application of coagulants such as $8 \mathrm{~g} / \mathrm{L}$ of polyferric sulfate in $\mathrm{pH} 6,10 \mathrm{~g} / \mathrm{L}$ of $\mathrm{FeCl}_{3}$ in $\mathrm{pH} 8$, and $12 \mathrm{~g} / \mathrm{L}$ of $\mathrm{Fe}_{2}\left(\mathrm{SO}_{4}\right)_{3}$ in $\mathrm{pH} 7.5$ for the treatment of leachate, which is considered a type of industrial wastewater, suggested that the efficiencies of these coagulants in the removal of turbidity and COD were respectively $56.38 \%$ and $89.79 \%$ for polyferric sulfate, $68 \%, 65 \%$, and $98.85 \%$ for $\mathrm{FeCl}_{3}$, and $55.87 \%$ and $94.13 \%$ for $\mathrm{Fe}_{2}\left(\mathrm{SO}_{4}\right)_{3}$, indicating the high rate of consumption of common coagulants in the treatment of wastewater (20).

The results of the present study showed that the percentage of turbidity removal depended on the initial concentration of turbidity in MWFs. For $\mathrm{CaCl}_{2}$, the optimal concentration was $6 \%$, while for alum, oil was better separated from emulsion in lower concentrations $(2 \%-4 \%)$. Since the practical concentration of MWFs in workshops is commonly $6 \%$ and $\mathrm{CaCl}_{2}$ leaves less environmental impacts compared to alum, $\mathrm{CaCl}_{2}$ is considered a higher priority in the destabilization of oil emulsions. Optimal value for consumption of $\mathrm{CaCl}_{2}$ in the current work was $3.6 \mathrm{~g} / \mathrm{L}$, and turbidity was reduced to an acceptable value (20 NTU). COD reduction was relatively low in comparison with the results of this research, which may due to the type of MWF wastewater being studied. To confirm the results obtained from the experimental data, three additional experiments were performed for each coagulant and the results were compared. Verification of the experimental results at optimum conditions for the four coagulants are shown in Table 4.

The results indicate good agreement between the predictive data obtained from the models and the experimentally measured data (independent data).

\section{Conclusion}

Physical-chemical methods are recommended for the pretreatment of MWFs; among them, coagulationflocculation is one of the plain and usual methods. Although many coagulants are available for the treatment of water and wastewater, selecting the most effective coagulant for a specific wastewater still depends greatly on the results of laboratory jar testing. Calcium chloride as an uncommon coagulant for the treatment of wastewater was investigated in this study for MWFs wastewater treatment. Alum, ferric chloride, and ferric sulphate as conventional coagulants were applied to the same wastewater for performance comparison. The results showed calcium chloride had a higher removal efficiency in the reduction of organic load and suspended solids of MWF compared with the other three coagulants used for such industrial wastewater treatment. Furthermore, the results showed good agreement between experimental data and the predicted equation.

\section{Acknowledgments}

This study was funded by Qazvin University of Medical 
Sciences, Department of Environmental Health Engineering (IR.QUMS.REC.28.44.5997 code of ethics). The authors would like to express their gratitude to the authorities of Qazvin University of Medical Sciences for providing the experimental facilities in the laboratory of the Environmental Health Engineering Department.

\section{Ethical issues}

The authors certify that all data collected during the study is as stated in this manuscript, and no data from the study has been or will be published separately elsewhere.

\section{Competing interests}

The authors declare that they have no competing interests.

\section{Authors' contributions}

All authors contributed equally to data collection and article approval.

\section{References}

1. Byers JP. Metalworking Fluids. 3rd ed. Boca Raton: CRC Press; 2016.

2. Grossi M, Ricco B. A portable electronic system for in-situ measurements of oil concentration in MetalWorking fluids. Sens Actuators A Phys 2016; 243: 7-14. doi: 10.1016/j. sna.2016.03.006.

3. Jagadevan S, Graham NJ, Thompson IP. Treatment of waste metalworking fluid by a hybrid ozone-biological process. J Hazard Mater 2013; 244-245: 394-402. doi: 10.1016/j. jhazmat.2012.10.071.

4. Demirbas E, Kobya M. Operating cost and treatment of metalworking fluid wastewater by chemical coagulation and electrocoagulation processes. Process Saf Environ Prot 2017; 105: 79-90. doi: 10.1016/j.psep.2016.10.013.

5. Thill PG, Ager DK, Vojnovic B, Tesh SJ, Scott TB, Thompson IP. Hybrid biological, electron beam and zero-valent nano iron treatment of recalcitrant metalworking fluids. Water Res 2016; 93: 214-21. doi: 10.1016/j.watres.2016.02.028.

6. Khuri AI, Mukhopadhyay S. Response surface methodology. Wiley Interdiscip Rev Comput Stat 2010; 2(2): 128-49. doi: 10.1002/wics.73.

7. Moradnia M, Panahi fard M, Dindarlo K, Ali Jamali H. Optimizing potassium ferrate for textile wastewater treatment by RSM. Environ Health Eng Manag J 2016; 3(3): 137-42. doi: 10.15171/ehem.2016.12.

8. Montgomery DC. Design and Analysis of Experiments. 8th ed. John Wiley Sons; 2008.

9. Emamjomeh MM, Jamali HA, Moradnia M. Optimization of Nitrate Removal Efficiency and Energy Consumption Using a Batch Monopolar Electrocoagulation: Prediction by RSM Method. J Environ Eng 2017; 143(7): 401-12. doi:
10.1061/(ASCE)EE.1943-7870.0001210.

10. Hasan HA, Abdullah SRS, Kamarudin SK, Kofli NT. Response surface methodology for optimization of simultaneous COD, NH4+-N and $\mathrm{Mn} 2+$ removal from drinking water by biological aerated filter. Desalination 2011; 275(1): 50-61. doi: 10.1016/j.desal.2011.02.028.

11. Arslan-Alaton I, Akin A, Olmez-Hanci T. An optimization and modeling approach for $\mathrm{H} 2 \mathrm{O} 2 / \mathrm{UV}-\mathrm{C}$ oxidation of a commercial non-ionic textile surfactant using central composite design. J Chem Technol Biotechnol 2010; 85(4): 493-501. doi: 10.1002/jctb.2315.

12. Yu Y, Zhou X, Wu S, Wei T, Yu L. High-yield production of the human lysozyme by Pichia pastoris SMD1168 using response surface methodology and high-cell-density fermentation. Electron J Biotechnol 2014; 17(6): 311-6. doi: 10.1016/j.ejbt.2014.09.006.

13. Gutierrez G, Lobo A, Benito JM, Coca J, Pazos C. Treatment of a waste oil-in-water emulsion from a copperrolling process by ultrafiltration and vacuum evaporation. J Hazard Mater 2011; 185(2): 1569-74. doi: 10.1016/j. jhazmat.2010.10.088.

14. Moscoso F, Deive FJ, Villar P, Pena R, Herrero L, Longo $\mathrm{MA}$, et al. Assessment of a process to degrade metal working fluids using Pseudomonas stutzeri CECT 930 and indigenous microbial consortia. Chemosphere 2012; 86(4): 420-6. doi: 10.1016/j.chemosphere.2011.10.012.

15. Tong K, Zhang Y, Chu PK. Evaluation of calcium chloride for synergistic demulsification of super heavy oil wastewater. Colloids Surf A Physicochem Eng Asp 2013; 419: 46-52. doi: 10.1016/j.colsurfa.2012.11.047.

16. Canizares P, Martinez F, Jimenez C, Saez C, Rodrigo MA. Coagulation and electrocoagulation of oil-in-water emulsions. J Hazard Mater 2008; 151(1): 44-51. doi: 10.1016/j.jhazmat.2007.05.043.

17. Canizares P, Garcia-Gomez J, Martinez F, Rodrigo MA. Evaluation of a simple batch distillation process for treating wastes from metalworking industries. J Chem Technol Biotechnol 2004; 79(5): 533-9. doi: 10.1002/jctb.1021.

18. Tir M, Moulai-Mostefa N. Optimization of oil removal from oily wastewater by electrocoagulation using response surface method. J Hazard Mater 2008; 158(1): 107-15. doi: 10.1016/j.jhazmat.2008.01.051.

19. Zhang W, Xiao P, Wang D. Central treatment of different emulsion wastewaters by an integrated process of physicochemically enhanced ultrafiltration and anaerobicaerobic biofilm reactor. Bioresour Technol 2014; 159: 1506. doi: 10.1016/j.biortech.2014.02.067.

20. Liu X, Li XM, Yang Q, Yue X, Shen TT, Zheng W, et al. Landfill leachate pretreatment by coagulation-flocculation process using iron-based coagulants: optimization by response surface methodology. Chem Eng J 2012; 200-202: 39-51. doi: 10.1016/j.cej.2012.06.012. 